\title{
PENGARUH ATTITUDE, REWARD, DAN PUNISHMENT TERHADAP TURN OVER KARYAWAN CV. CAHAYA MOTOR
}

\author{
M. Harun Arrasyid ${ }^{1}$, Fachrudy Asj' ari, S. ${ }^{2}$ \\ Mahasiswa Program Studi Manajemen ${ }^{1}$ \\ Universitas PGRI AdiBuana Surabaya \\ Mharun559@gmail.com
}

\begin{abstract}
Employee turnover is defined as the desire of the employee's intention to leave. This is because perhaps the rewards given to employees for their work such as giving bonuses and salaries are less satisfying for employees. Then the employee can also leave because of the work attitude of the employee to make a loss for the company. Penalties for employees need to be given so that employees who violate and have a bad work attitude will be even better. Employees of CV. Light Motor is used as a population and a sample of 59 respondents. Then a questionnaire is given and the respondent's answers will be analyzed with multiple linear regression tests. The results are found if the Attitude, Reward and Punishment variables have a significant influence on the employee turnover variable CV. Motorcycle Light. Then Attitude, Reward and Punishment has a simultaneous influence on employee turnover of CV. Motorcycle Light.
\end{abstract}

Keywords: Attitude, Reward, Punishment, and Employee Turnover

\section{PENDAHULUAN}

Bisnis jual beli mobil sudah menjadi usaha yang tidak asing lagi. Bisnis ini semakin hari ke hari banyak yang mendirikan. Persaingan antar penjual khususnya mobil bekas sangatlah ketat. Banyak juga yang mendirikan showroom mobil bekas untuk dijual kembali kekonsumen. Hal ini akan menjadi persaingan sehingga pihak perusahaan atau showroom harus mampu memberikan pengembangan karyawannya agar dapat membantu menjual mobil sebanyak-banyaknya. Sumber daya manusia disini sangat perlu ditingkatkan. Salah satu utuk meningkatkan sumber daya manusia yaitu dengan memperhatikan sikap kerja karyawan. ,Karyawan haruslah mempunyai sikap kerja yang baik dan sopan terhadap perusahaan maupun karyawan yang lainnya. Sikap kerja juga bisa tergantung pada lingkungan kerjanya. Lingkungan kerja yang nyaman dan mendukung aktivitas kerja karyawan akan membuat karyawan merasakan ketenangan dan selalu berbuat yang terbaik bagi perusahaannya. Karyawan juga dituntut utuk selalu mengendalikan diri ketika terjadi masalah atau tekanan kerja yang berat. Dengan sikap tenang pekerjaan yang diberikan perusahaan kepada karyawan akan cepat terselesaikan.

Karyawan juga harus diberikan reward atau imbalan bagi yang bisa membantu mengembangkan perusahaan. Imbalan bisa berupa gaji atau kenaikan pangkat agar karyawan tersebut bisa lebih semangat dalam menjalankan tugas-tugas yang diberikan perusahaan. Akan tetapi karyawan juga ada yang mempunyai sikap kerja yang kurang baik. Karyawan yang tidak baik dalam sikap kerjanya perlu mendapatkan punishment atau hukuman. Hukuman bisa berupa peringatan atau yang paling berat yaitu diberhentikan kerja. Memberi hukuman seperti ini agar karyawan dalam bekerja tidak seenaknya dan hal ini akan membantu karyawan patuh pada peraturan perusahaan. Akan tetapi karyawan kadang mempunyai rasa ingin keluar dari pekerjaannya karena mereka ingin mencari pekerjaan yang lebih baik.

Turnover karyawan terjadi karena karyawan tersebut mungkin kurang dengan bonus atau gaji yang diberikan perusahaan sehingga karyawan merasa kebutuhannya belum tercukupi dan belum sejahtera.

Karyawan CV. Cahaya Motor sendiri jarang ada karyawan yang ingin keluar dari pekerjaannya. Akan tetapi perusahaan harus mempunyai sikap untuk terus 
mensejahterakan konsumen mereka. Mungkin diberikan gaji dan bonus yang sebanding dengan hasil kerja karyawan. Akan tetapi perusahaan perlu memperhatikan sikap kerja karyawannya juga. Apabila ada karyawan yang mempunyai sikap kerja kurang baik dan merugikan perusahaan ataupun karyawan lainnya. Perusahaan perlu memberikan hukuman baik itu hukuman ringan maupun berat. Hal ini akan menjadikan karyawan di CV. Cahaya Motor lebih disiplin dan taat akan aturan yang berlaku diperusahaan.

\section{TINJAUAN PUSTAKA}

\section{Attitude}

Schermerhorn, dkk dalam Muhammad Muhson (2017:21), Sikap diartikan sebagai respon seseorang pada lingkungannya dimana seseorang akan terlihat sikapnya apabila mereka suka atau tak suka akan sesuatu hal.

Sikap juga diartikan sebagai rasa berkorban seseorang baik jasmani ataupun pikiran sehingga akan menghasilkan prestasi dan imbalan. (Hasibuan, 2001 : 94).

Ditarik kesimpulan kalau sikap kerja diartikan sebagai respon karyawan kepada lingkungan sekitar kerjanya. Karyawan akan menanggapi dengan baik jika lingkungan kerja nya memberi rasa nyaman kepada dirinya.

Menurut Ronen (2003), indikator sikap kerja sebagai berikut :

1.Mengendalikan diri

Mengendalikan diri sendiri tidaklah mudah. Butuh sikap tenang agar diri kita sendiri dapat dikendalikan sehingga kita akan tetap tenang apabila ada masalah yang dihadapi.

\section{Fleksibel}

Jam kerja yang fleksibel akan menjadikan karyawan memiliki kualitas kerja yang baik.

\section{Komitmen Kerja}

Sebagai sikap karyawan yang memiliki rasa ingin yang kuat kepada pekerjaannya sehingga mereka merasa nyaman akan pekerjaan itu sendiri.

\section{Reward}

Nugroho dalam Koencoro (2013:2) Reward sebagai imbalan atau hadiah bagi karyawan yang dapat terus meningkatkan kinerjanya.

Reward juga diartikan sebagai bentuk rasa terima kasih perusahaan kepada karyawan ada prestasi yang telah dicapai. (Purnama, 2015:13).

Dapat diambil simpulan reward dijadikan sebagai imbalan atau pemberian kepada seseorang yang telah membantu mencapai tujuan yang diinginkan perusahaan.

Mahmudi (2013:187) Indikator reward yaitu:

1.Bonus dan Gaji

bonus dan Gaji diberikan untuk menghargai kerja keras karyawan atas kerjanya.

2. Karyawan harus sejahtera

karyawan yang sejahtera harus diperhatikan oleh perusahaan. Karyawan yang sejahtera akan merasa dirinya dihargai dan diperhatikan.

3. Mengembangkan karir

Mengembangkan karir bagi karyawan perlu dilakukan karena menjadikan karyawan termotivasi untuk menaikkan karirnya.

4.Penghargaan psikologis dan sosial

Penghargaan perlu di berikan baik psikologis maupun sosial karena penghargaan akan menumbuhkan motivasi lebih bagi karyawan serta meningkatkan semangat kerja.

\section{Punishment}

Menurut Hasibuan (2009:37) Punishment (hukuman) diartikan sebagai hukuman bagi karyawan yang melakukan perbuatan secara sadar karyawan untuk menjatuhkan orang lain. Hukuman bagi karyawan bisa berupa diberikan sanksi atau peringatan agar karyawan tersebut tidak mengulanginya lagi (Mangkunegara, 2013).

Ditarik simpulan hukuman artinya pemberian sanksi atau peringatan bagi karyawan yang sengaja berbuat kesalahan agar tidak merugikan bagi perusahaan juga bagi karyawan 
lainnya.

Menurut Rivai dalam Koencoro (2013:4) Indikator punishment yaitu:

1. Hukum Ringan

Hukuman ini berupa peringatan atau teguran bagi karyawan.

2. HukumSedang

Penurunan gaji atau pembatalan kenaikan gaji.

\section{Hukum Berat}

Pemberhentian kerja atau pencopotan jabatan pantas diberikan kepada karyawan yang melakukan pelanggaran berat di perusahaaan.

\section{Turnover Karyawan}

Yucel (2012:2) turnover intention diartikan sebagai karyawan yang berniat untuk keluar dari sebuat perusahaan karena sudah tidak nyaman dengan lingkungan kerjanya.

Waspodo, Nurul dan Widya (2013) mengartikan turnover intention sebagai rasa ingin seseorang karyawan untuk keluar dari perusahaan dengan tujuan memilih pekerjaan lain yang dirasa lebih baik dari pekerjaannya dulu.

Ditarik kesimpulan turnover karyawan diartikan sebagai peninggalan pekerjaan oleh karyawan karena merasa pekerjaannya saat ini kurang nyaman dan berniat untuk memilih lagi pekerjaan diperusahaan lain yang lebih baik.

Chen dan Francesco dalam Dharma, (2013:4) yaitu:

1. Memikirkan untuk keluar

Karyawan yang kurang nyaman dengan kerjanya akan memikirkan untuk keluar dari pekerjaannya.

2.Ingin mencari lowongan

Mencari pekerjaan lain mungkin dirasa solusi bagi karyawan untuk mencari pekerjaan yang lebih baik.

3. Keinginan meninggalkan organisasi sementara

Meninggalkan sebuah organisasi sementara waktu mungkin dirasa perlu bagi karyawan untuk mencari organisasi baru untuk menambah pengalaman.

\section{Kerangka konseptual}

Berikut kerangka konseptual disajikan dibawah ini:

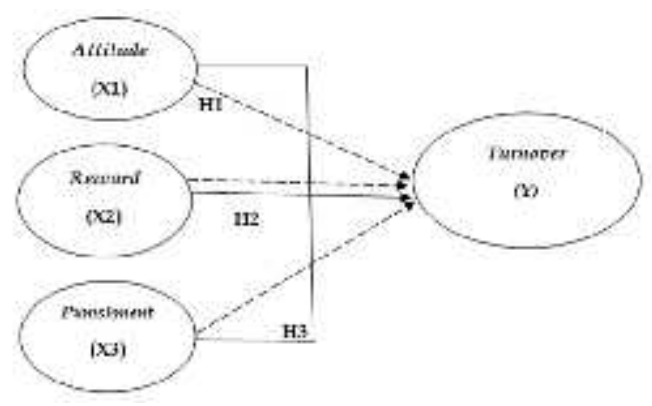

\section{Gambar 1. Kerangka Konseptual}

\section{Hipotesis}

Hipotesis akan dipaparkan sebagai berikut:

H1: Attitude memiliki pengaruh kepada turnover karyawan CV. Cahaya Motor.

H2: Reward mempunyai pengaruh kepada turnover karyawan CV. Cahaya Motor.

H3: Punishment memiliki pengaruh kepada turnover karyawan CV. Cahaya Motor.

H4: Attitude, Reward dan Punishment mempunyai pengaruh simultan kepada turnover karyawan CV. Cahaya Motor.

\section{METODE PENELITIAN}

Ada 59 Karyawan CV. Cahaya Motor digunakan sebagai populasi sekaligus sampel. Sampel jenuh digunakan sebagai teknik pengambilan sampel. Kemudian disebar kuesioner 
Journal of Sustainability Business Research (JSBR)

Vol-1,Issue-1,Desember (JSBR)

E-ISSN: 2746-8607

http://jurnal.unipasby.ac.id/index.php/jsbr

dan hasil jawaban responden dianalisis datanya dengan analisis regresi linier berganda.

\section{HASIL PENELITIAN DAN PEMBAHASAN}

Berikut hasil analisis data yang akan ditampilkan sebagai berikut:

\section{Validity Test}

Berikut validity test akan dipaparkan sebagai berikut:

Tabel 1.

Validity Test $\left(\mathbf{X}_{1}\right)$

\begin{tabular}{|c|c|c|}
\hline (V) & $\mathbf{R}_{\text {hitung }}$ & $\mathbf{R}_{\text {tabel }}$ \\
\hline \multirow{6}{*}{$\mathrm{X}_{1}$} & .430 & \multirow{6}{*}{$>.256$} \\
\hline & .727 & \\
\hline & .778 & \\
\hline & .735 & \\
\hline & .552 & \\
\hline & .726 & \\
\hline \multirow{8}{*}{$X_{2}$} & .430 & \multirow{8}{*}{$>.256$} \\
\hline & .492 & \\
\hline & .577 & \\
\hline & .672 & \\
\hline & .704 & \\
\hline & .691 & \\
\hline & .615 & \\
\hline & .495 & \\
\hline \multirow{6}{*}{$X_{3}$} & .441 & \multirow{6}{*}{.256} \\
\hline & .718 & \\
\hline & .758 & \\
\hline & .776 & \\
\hline & .563 & \\
\hline & .662 & \\
\hline \multirow{6}{*}{ Y } & .520 & \multirow{6}{*}{.256} \\
\hline & .835 & \\
\hline & .644 & \\
\hline & .780 & \\
\hline & .780 & \\
\hline & .608 & \\
\hline
\end{tabular}

Dapat dilihat diatas $\mathrm{R}_{\text {hitung }}>$ dari $\mathrm{R}_{\text {tabel }}$ artinya semua pernyataan pada variabel valid.

\section{Realibility Test}

Berikut akan dipaparkan hasil realibility test:

Tabel 2.

Realibility Test

\begin{tabular}{|c|c|c|}
\hline$(\mathbf{V})$ & $\begin{array}{c}\text { Cronbach } \\
\text { Alpha }\end{array}$ & Nilai Kritis \\
\hline$\left(\mathrm{X}_{1}\right)$ & .736 & .60 \\
\hline$\left(\mathrm{X}_{2}\right)$ & .722 & .60 \\
\hline$\left(\mathrm{X}_{3}\right)$ & .791 & .60 \\
\hline$(\mathrm{Y})$ & .733 & .60 \\
\hline
\end{tabular}

Dilihat dari tabel diatas nilai cronbach alpha $>.60$. artinya pernyataan pada semua variabel reliable.

\section{Normality Test}

Berikut akan dipaparkan hasil realibility test: 
Vol-1,Issue-1,Desember (JSBR)

E-ISSN: 2746-8607

http://jurnal.unipasby.ac.id/index.php/jsbr

Tabel 3.

\begin{tabular}{|c|c|}
\hline & $\begin{array}{c}\text { Unstandardised } \\
\text { Residual }\end{array}$ \\
\hline $\mathrm{N}$ & 59 \\
\hline Uji Statistik & .074 \\
\hline Asymp.sig(2-tailed) & $.200^{\mathrm{c}}$ \\
\hline
\end{tabular}

Apabila nilai asymp.sig $.200>.05$ diartikan variabel berdistribusi normal.

\section{Multicolinierity Test}

Berikut hasil multicolinierity test akan disajikan lewat tabel berikut:

Tabel 4.

Multicolinierity Test

\begin{tabular}{|c|c|c|}
\hline$(\mathbf{V})$ & Tolerance & VIF \\
\hline$\left(\mathrm{X}_{1}\right)$ & .380 & 2.632 \\
\hline$\left(\mathrm{X}_{2}\right)$ & .215 & 4.651 \\
\hline$\left(\mathrm{X}_{3}\right)$ & .230 & 4.355 \\
\hline
\end{tabular}

Nilai tolerance $>.10$ dan $\mathrm{VIF}<10$. Maka data diatas tidak terjadi multikolinieritas.

Heteroskedastisity Test

Berikut akan dipaparkan hasil heteroskedastisity test:

Tabel 5.

Heteroskedastisity Test

\begin{tabular}{|c|c|c|}
\hline$(\mathbf{V})$ & $\mathbf{T}$ & Sig \\
\hline$\left(\mathrm{X}_{1}\right)$ & .932 & .355 \\
\hline$\left(\mathrm{X}_{2}\right)$ & -1.338 & .186 \\
\hline$\left(\mathrm{X}_{3}\right)$ & -.792 & .431 \\
\hline
\end{tabular}

Nilai Sig. >.05 sehingga variabel $\mathrm{X}_{1}, \mathrm{X}_{2}$ dan $\mathrm{X}_{3}$ tidak terjadi heteroskedastisitas.

\section{Autocorelation Test}

Berikut hasil autocorrelation test akan disajikan lewat tabel berikut:

Tabel 6.

Autocorelation Test

\begin{tabular}{|c|}
\hline DW \\
\hline 2.014 \\
\hline
\end{tabular}

Nilai DW 2.014 > DU 1.6875 artinya tidak terjadi autokorelasi.

\section{Uji T}

Hasil uji t akan disajikan berikut:

Tabel 7.

\begin{tabular}{|c|c|c|}
\hline Koefisien Standar & T & Sig \\
\hline$($ Konstan $)$ & -1.785 & .080 \\
\hline$\left(\mathrm{X}_{1}\right)$ & 5.729 & .000 \\
\hline$\left(\mathrm{X}_{2}\right)$ & 6.784 & .000 \\
\hline$\left(\mathrm{X}_{3}\right)$ & -4.435 & .000 \\
\hline
\end{tabular}

Uji T

Dari perhitungan diatas diketahui jika:

1. Variabel $\left(\mathrm{X}_{1}\right) \mathrm{t}_{\text {hitung }} 5.729$ dengan nilai sig .000. Sehingga $(.000<.05)$ artinya variabel $\mathrm{X}_{1}$ mempunyai pengaruh pada variabel $\mathrm{Y}$.

2. Variabel $\left(\mathrm{X}_{2}\right) \mathrm{t}_{\text {hitung }} 6.784$ dengan nilai sig .000. Sehingga $(.000<.05)$ artinya variabel $\mathrm{X}_{2}$ mempunyai pengaruh pada variabel $\mathrm{Y}$.

3. Variabel $\left(\mathrm{X}_{3}\right) \mathrm{t}_{\text {hitung }}-4.435$ dengan nilai sig .000. Sehingga $(.000<.05)$ artinya variabel $\mathrm{X}_{3}$ mempunyai pengaruh pada variabel $\mathrm{Y}$. 
Uji F

Hasil uji t akan disajikan berikut:

\section{Tabel 8.}

Uji F

\begin{tabular}{|c|c|c|}
\hline Model & F & Sig \\
\hline Regresi & 77.003 & .000 \\
\hline
\end{tabular}

Dari hasil uji $f$ diatas nilai $f_{\text {hitung }} 77.003$ dengan nilai sig $.000<.05$ artinya variabel $\left(\mathrm{X}_{1}\right),\left(\mathrm{X}_{2}\right)$ dan $\left(\mathrm{X}_{3}\right)$ mempunyai pengaruh seacara bersama-sama pada variabel $\mathrm{Y}$.

\section{SIMPULAN}

1. Variabel (X1) mempunyai pengaruh pada variabel (Y).

Artinya sikap kerja yang baik akan membuat karyawan betah pada pekerjaannya sehingga tidak terjadi turnover pada karyawan.

2. Variabel (X2) mempunyai pengaruh pada variabel (Y).

Artinya reward perlu diberikan kepada karyawan yang bekerja dengan baik dan mampu membantu mengembangkan perusahaan. Apabila perusahaan tidak mengahragai kerja keras karyawan mungkin karyawan tersebut akan mempunyai rasa ingin keluar dari pekerjaannya dan mencari lagi pekerjaan yang lebih baik dari sebelumnya.

3. Variabel (X3) mempunyai pengaruh pada variabel (Y).

Artinya punishment perlu dilakukan oleh perusahaan jika ada karyawan yang berbuat kesalahan dan sengaja. Sehingga akan merugikan perusahaan serta karyawan yang lainnya. Jika tidak dilakukan hukuman pada karyawan yang salah akan membuat karyawan lain merasa ingin keluar dari perusahaan tersebut karena apabila diteruskan bekerja akan membuat karyawan tersebut ikut tidak disiplin dan melanggar peraturan juga serta akan membuat karyawan tesebut tidak berkembang karena perusahaan tempat bekerjanya tidak mendidik karyawan untuk disiplin.

4. Variabel (X1), (X2), dan (X3) mempunyai pengaruh simultan pada variabel (Y). Artinya sikap kerja yang baik akan memberikan kemajuan bagi perusahaan. Sehingga perlu perusahaan menghargai karyawan dengan memberikan imbalan atau penghargaan kepada karyawan agar tidak terjadi kelalaian dalam kerja karyawan sehingga hukuman bagi karyawan yang melakukan kesalahan berkurang dan pada akhirnya sikap rasa ingin keluar pada karyawan berkurang dan semakin mencintai pekerjaannya.

\section{IMPLIKASI}

Sikap kerja di CV. Cahaya Motor perlu ditingkatkan lagi karena betapa pentingnya sikap kerja karyawan untuk memajukan perusahaan. Sikap kerja karyawan yang baik dan disiplin akan menjadikan perusahaan semakin Berjaya dan perlu perusahaan memberikan reward pada karyawan agar semakin termotivasi untuk berbuat baik dan memajukan perusahaan. Imbalan bagi karyawan juga bisa mengurangi rasa ingin keluar akan pekerjaanya. Akan tetapi perusahaan perlu juga melakukan hukuman bagi karyawan yang sengaja berbuat salah dan merugikan banyak pihak.

\section{KETERBATASAN PENELITIAN}

Ketika menyebar kuesioner banyak karyawan yang menjawab pernyataan tidak sesuai keadaan yang ada diperusahaan. Keterbatasan waktu dan biaya menjadi sedikit kendala pada pengambilan data.

\section{DAFTAR RUJUKAN}


http://jurnal.unipasby.ac.id/index.php/jsbr

Hasibuan, Malayu. 2001. Manajemen Sumber Daya Manusia. Jakarta: PT Bumi Aksara.

Hasibuan, Malayu S.P. 2009. Manajemen Sumber Daya Manusia. (Edisi revisi cetakan ke tiga belas). Jakarta: PT Bumi Aksara.

Hasibuan, Malayu S.P. 2016. Manajemen Sumber Daya Manusia. Edisi Revisi. Jakarta: Penerbit PT Bumi Aksara.

Yucel, Ilhami. 2012. Examining the Relationships among Job Satisfaction, Organizational Commitment, and Turnover Intention : An Empirical Study. International Journal of Business and Management. Vol. 7. No. 20, 44-58.

Mahmudi. 2013. Manajemen Kinerja Sektor Publik. Sekolah Tinggi Ilmu Manajemen YKPN. Yogyakarta.

AA. Anwar Prabu Mangkunegara. 2013. Manajemen Sumber Daya Manusia Perusahaan. Remaja Rosdakarya. Bandung.

Abdurahman. Maman. Sambas. Ali Muhidin. Ating Somantri. 2011. Dasar-dasar Metode Statistika Untuk Penelitian. Bandung. Pustaka Setia.

Agung AWS Waspodo et., al. 2013. Pengaruh Kepuasan Kerja dan Stres Kerja terhadap Turnover Intention pada Karyawan PT. Unitex di Bogor. Jurnal Riset Manajemen Sains Indonesia. Vol. 4. No. 1.

Agus, Dharma. 2013. Manajemen Supervisi. Penerbit : Raja Grafindo Persada. Jakarta.

Robbins SP, dan Judge. 2008. Perilaku Organisasi. Buku 2, Jakarta : Salemba Empat Hal 256.

Ronen, T. 2003. Cognitive Development Therapy with Children. New York: John Wiley \& Sons 
Journal of Sustainability Business Research (JSBR)

Vol-1,Issue-1,Desember (JSBR)

E-ISSN: 2746-8607

http://jurnal.unipasby.ac.id/index.php/jsbr 